\title{
An ileal hyperplastic polyp comorbidity in the case of acute appendicitis
}

\author{
Cesim IRSI*1, Safak Karacay ${ }^{2}$ \\ ${ }^{1}$ Department of Pediatric Surgery, Istanbul Fatih Sultan Mehmet Teaching And Research Hospital, Istanbul, Turkey \\ ${ }^{2}$ Department of Pediatric Surgery, Liv International Hospital, Istanbul, Turkey
}

Received: April 27, 2016

DOI: $10.5430 /$ crcp.v3n4p37
Accepted: July 24, 2016

Online Published: August 1, 2016

\begin{abstract}
Introduction: We aimed to underline the importance of the covert comorbidities like ileal intestinal polyps in pediatric abdominal operations for appendicitis.

Case: A 10-year-old girl was referred to us from the emergency ward with the complaints of abdominal pain and vomiting. After detailed examination, we decided to conduct an abdominal exploration in suspicion of potential acute appendicitis. During the laparotomy, an acute simple appendicitis was found and appendectomy was performed. We further explored the abdomen to rule out a possible Meckel diverticulitis, during which an ileal intraluminal mass was palpated about $10 \mathrm{~cm}$ proximal to the intestinal ileocecal valve. We performed enterotomy and resected the polypoid mass completely. The histopathological reports were lymphoid hyperplasia for the appendicitis and intestinal hyperplastic polyp for the polypoid mass. Follow up of the patient after 6 months was eventless.

Conclusions: Comorbidities like intestinal polyps should be part of the considerations during the abdominal explorations for acute appendicitis. Missing an ileal polyp may lead to a second operation.
\end{abstract}

Key Words: Appendicitis, Polyp, Comorbidity, Children

\section{INTRODUCTION}

Acutely inflamed appendix is one of the most common causes of abdominal explorations in children. While many misleading factors exist for negative appendectomy, an acutely inflamed appendix may obscure another intra abdominal pathology. An extended abdominal exploration after a suspicious appendicitis inoperatively may decrease the chances of a missing comorbidities, which may require a second operation otherwise.

\section{CASE REPORT}

A 10-year-old girl was referred to us from the emergency ward with the complaints of abdominal pain and vomiting.
After detailed examination, we decided to conduct an abdominal exploration with the diagnosis of acute appendicitis. During the laparotomy, an acute simple appendicitis was found and appendectomy was performed. We further explored the abdomen to rule out Meckel diverticulitis, during which an ileal intraluminal mass was palpated about $10 \mathrm{~cm}$ proximal to the ileocecal valve. The mass was about $2 \mathrm{~cm}$ in diameter and located at ileal intestinal mesenteric side, without a stalk formation. There was no evidence of any ischemic or inflammatory intestinal segmental change suggesting a possible leading point for invagination. We just performed an enterotomy and resected the polypoid mass completely. The histopathological reports were as lymphoid hyperplasia

\footnotetext{
*Correspondence: Cesim IRSI; Email: csmirsi@yahoo.com; Address: Department of Pediatric Surgery, Istanbul Fatih Sultan Mehmet Teaching And Research Hospital, Istanbul, Turkey.
} 
for the appendicitis and intestinal hyperplastic polyp for the polypoid mass. The patient had neither previous history of gastrointestinal polypoid symptoms nor her family history suggests a polypoid disease. Follow up of the patient after 6 months was uneventful.

\section{Discussion}

Gastrointestinal polyps are less commonly observed in children than in adults. Intestinal epithelium or submucosal intraluminal overgrowth leads to their formation. ${ }^{[1]}$ The major presentations of gastrointestinal polyps in children are rectal bleedings and non-specific abdominal pain. Polyps can also change the intestinal peristalsis and by acting as leading points, can cause invagination of the affected intestinal segment, which is believed to be the main reason of subtle or non-spesific abdominal pain owed to the periodical invagination attacks. ${ }^{[2,3]}$

Most pediatric intestinal polyps are defined as benign, sporadic, in a few cases nonfamilial (non hereditary) and without malignant transformation (see Figures 1-2). They are classified as juvenile, non-hereditary and hyperplastic, hereditary and hamartomatous like Peutz-Jeghers, Juvenile polyposis, syndrome of Cowden, syndrome of Ruvalcaba-Myhre-Smith and hereditary adenomatous types like familial polyposis coli, Gardner and Turcot syndromes. Hereditary hamartomatous polyps and mainly hereditary adenomatous polyposis have malign transformation potential and may be seen together with extraintestinal benign and malign neoplasms. ${ }^{[4-6]}$

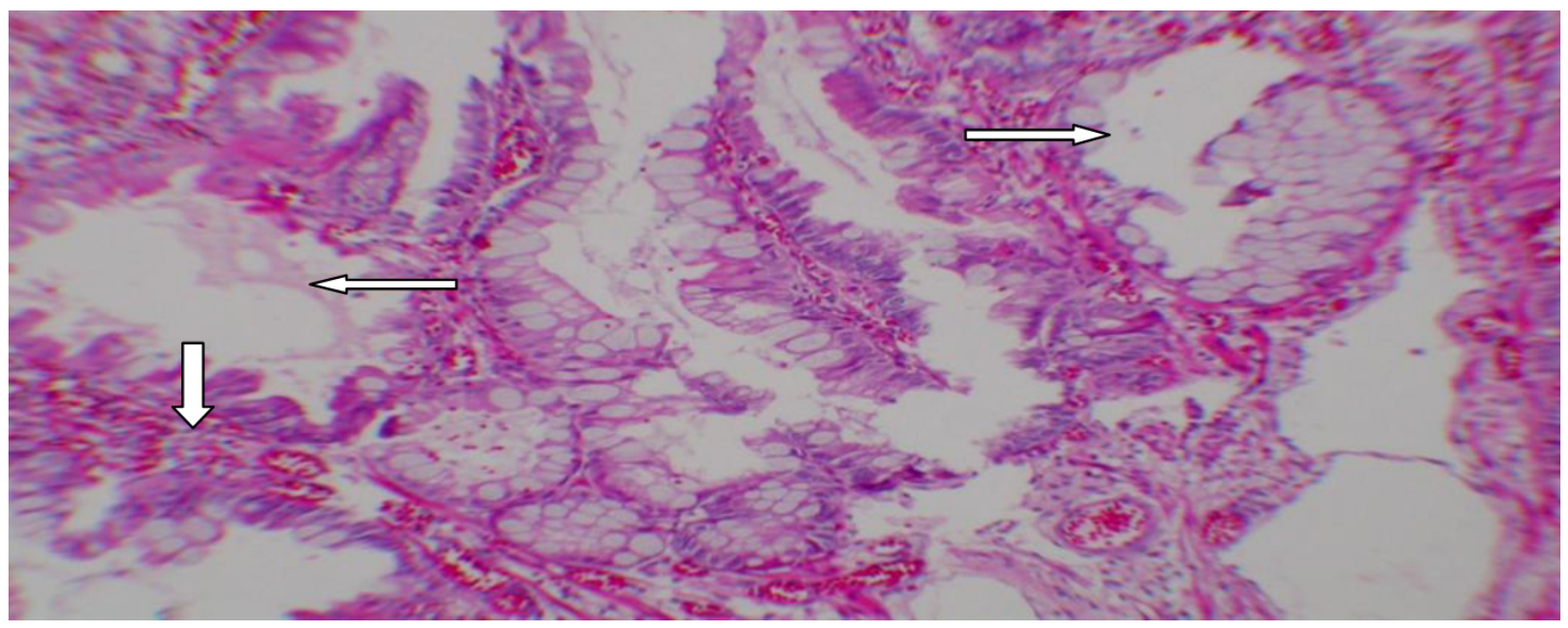

Figure 1. Crypts are dilated (thin arrow), with the proliferation of the lining epithelium (thick arrow), $(\mathrm{H} \& \mathrm{E} \times 100)$.



Figure 2. The polyp with dilated crypts and proliferated epithelium. Papillary proliferation in the crypt lumen (arrow) is observed $(\mathrm{H} \& \mathrm{E} \times 200)$. 
Although intestinal polypoidal nodular hyperplasia can be seen in all age groups, they are more common in pediatric age groups ${ }^{[6]}$ Rectal and ileocecal intestinal segments are the most common sites. Intestinal polypoidal hyperplasias are characterized as benign lesions and viral or parasitic infections are their main etiological factors. Commonly, they don't occur in stalk formation (as sessile) and mostly they are in solid appearance. ${ }^{[6,7]}$ Sometimes more than one intestinal polypoidal hyperplasias can be observed at different point of intestinal segment.

Patients usually suffer from non-specific abdominal pain and anemia resulting from chronic subtle hemorrhage. In the etiology of intussusception; polyps have an important role, acting as a trigger or leading point. Usually, simple local excision of them is sufficient. Sometimes spontaneous remission of these polyps may occur. ${ }^{[6,7]}$

The rectosigmoidal segment of intestin is the most common site for polyps to occur, followed by the other side of intestinal segments. Multiple segmental diseases may also be observed. Patients with the following features should be evaluated endoscopically for polypoidal diseases: Patients with positive family history, symptomatic patients during follow up and patients with extraintestinal polyp related diseases. ${ }^{[6-9]}$

Wireless capsule endoscopy is a technology developed recently for the endoscopic exploration of the small bowel which otherwise can not be visualized by conventional techniques. It is first and essential indication was occult gastrointestinal bleeding and intestinal polyp like diseases. It's use has expanded progressively and is nowadays considered as an important diagnostic method in pediatric gastroenterology, although the literature on this topic is not as extensive as in adults. . $^{[8,10,13,14]}$

The invaginations caused by ileal polyps are commonly ileoileal or jejunoileal in nature which do not act like the ileocecal ones. These intussusceptions cannot be treated with hydrostatic, pneumatic reductions or by milking maneuver. ${ }^{[11,12]}$ Open or laparoscopic surgical resections are mandatory for their treatment. Generally, simple surgical removal of a polyp or a limited wedge resection without intestinal segmental resection and anastomosis is sufficient. However, in cases of suspected malignancy, intestinal resection is required. ${ }^{[11,12,14]}$

The reported case is an example of an ileal polyp that was masked by an inflamed appendix and could be missed out easily if unchecked. The possibilities of comorbidities like pelvic masses, palpable intestinal intraluminal polyps and other intraabdominal pathologies should be kept in mind and checked during the pediatric abdominal explorations for appendicitis.

\section{Conclusions}

Any comorbidities should be thoroughly searched in cases of questionable or acutely inflamed appendix during the pediatric abdominal explorations.

\section{CONFlicts of InTEREST Disclosure}

The authors declare that they have no competing interests.

\section{REFERENCES}

[1] Erdman SH, Barnard J. Gastrointestinal polyps and polyposis syndromes in children. Curr Opin Ped. 2002; 14: 576-2. http://dx.d oi.org/10.1097/00008480-200210000-00003

[2] Vincent RA, Kathryn B. Polyps in Children. Clin Colon Rectal Surg. 2008; 21(4): 280-5. http://dx.doi.org/10.1055/s-0028-1 089943

[3] Durno CA. Colonic polyps in children and adolescents. Can J Gastroenterol. 2007; 21(4): 233-9. PMid: 17431512. http://dx.doi . org/10.1155/2007/401674

[4] Gupta SK, Fitzgerald JF, Croffie JM, et al. Experience with juvenile polyps in North American children: the need for pancolonoscopy. Am J Gastroenterol. 2001; 96 (6): 1695-7. PMid: 11419816. http://dx.doi.org/10.1111/j.1572-0241.2001.03860.x

[5] Colon AR, DiPalma JS, Leftridge CA. Intestinal lymphonodular hyperplasia of childhood: patterns of presentation. J Clin Gastroenterol. 1991; 13: 163-6. PMid: 2033223. http://dx.doi.org/10.1097 100004836-199104000-00009

[6] Attard TM, Cuffari C, Tajouri T, et al. Multicenter experience with upper gastrointestinal polyps in pediatric patients with familial ade- nomatous polyposis. Am J Gastroenterol. 2004; 99 (4): 681-6. PMid: 15089902. http://dx.doi.org/10.1111/j.1572-0241. 2004.04115.x

[7] Cynamon HA, Milov DE, Andres JM. Diagnosis and management of colonic polyps in children. J Pediatr. 1989; 114: 593-6. http://dx.doi.org/10.1016/S0022-3476 (89)80701-2

[8] Jalihal A, Misra SP, Arvind AS, et al. Colonoscopic polypectomy in children. J Pediatr Surg. 1992; 27(9): 1220-2. http://dx.doi.o $\mathrm{rg} / 10.1016 / 0022-3468$ (92) 90792-6

[9] Cooper HS. Intestinal neoplasms. In: Sternberg SS, ed. Diagnostic Surgical Pathology. Vol 2. 3rd ed. Philadelphia, Pa: Lippincott Williams \& Wilkins; 1999: 1424.

[10] De Ridder L, Van Lingen A, Taminiau J, et al. Rectal bleeding in children: endoscopic evaluation revisitied. Eur J Gastroenterol Hepatol. 2007; 19: 317-20. PMid: 17353696. http://dx.doi.org/10. 1097/MEG.0b013e328080caa6

[11] Blanch AJ, Perel SB, Acworth JP. Paediatric intussusception: epidemiology and outcome. Emerg Med Australas. 2007; 19(1): 45-50. http://dx.doi.org/10.1111/j.1742-6723.2007.00923 
[12] Shatrughan PS, Chandra SA, Prakash CJ, et al. Juvenile Polyps in the Small Intestine Presenting as Jejunojejunal Intussusception in a 10 Year-Old Child: Report of a Case. Surg Today. 2002; 32: 828-30. PMid: 12203065. http://dx.doi.org/10.1007/s0059502001 60

[13] Friedrich K, Gehrke S, Stremmel W, et al. First clinical trial of a newly developed capsule endoscope with panoramic side view for small bowel: a pilot study. J Gastroenterol Hepatol. 2013; 28: 149601. PMid: 23701674. http://dx.doi.org/10.1111/jgh.122 80

[14] Tokuhara D, Watanabe K, Okano Y, et al. Wireless capsule endoscopy in pediatric patients: The first series from Japan. J Gastroenterol. 2010; 45: 683-91. http://dx.doi.org/10.1007/s00535-010 $-0209-5$ 